\title{
Trail and kidney disease
}

\section{Corina Lorz ${ }^{1,2}$, Alberto Benito ${ }^{1}$, Alvaro C. Ucero ${ }^{1}$, Beatriz Santamaría ${ }^{1}$, Alberto Ortiz ${ }^{1}$}

${ }^{I}$ Renal and Vascular Research Laboratory, Fundacion Jimenez Diaz-UAM, Madrid, Spain, ${ }^{2}$ Current address: Basic Research Department, Epithelial Biomedicine Division, Molecular Oncology Unit, Ciemat, Madrid, Spain

\section{TABLE OF CONTENTS}

1. Abstract

2. Introduction

3. The TRAIL/TRAIL-receptor system

3.1. The TRAIL cytokine

3.2. TRAIL receptors

3.3. TRAIL signalling pathways

4. Expression of TRAIL and its receptors in the kidney

4.1. Healthy kidney

4.2. Diseased kidney

4.3. OPG: friend or foe?

5. Perspectives

6. References

\section{ABSTRACT}

TNF-related apoptosis-inducing ligand (TRAIL, TNFSF10) is a cytokine belonging to the TNF superfamily that has been recently linked to the pathogenesis of diabetic nephropathy. TRAIL may modulate cell survival and proliferation through interaction with two different receptors, TRAIL-R1 and TRAIL-R2, and the actions of TRAIL are regulated by three decoy receptors, TRAIL-R3, TRAIL-R4 and osteoprotegerin. Both TRAIL and their receptors are expressed by renal cells. In diabetic nephropathy the glomerular and tubulointerstitial expression of TRAIL is increased, and in tubular cells proinflammatory cytokines enhance TRAIL expression. Additionally, a high glucose microenvironment sensitizes tubular cells to apoptosis induced by TRAIL. Renal expression of OPG is increased in diabetic nephropathy and OPG counteracts the actions of TRAIL in cultured cells. Overall these data point to a role of TRAIL in the pathogenesis of diabetic nephropathy through interactions with other cytokines and hyperglycemia.

\section{INTRODUCTION}

Chronic kidney disease is characterized by a progressive loss of renal function leading to end-stage renal disease requiring substitution of renal function by dialysis or transplantation. The social and economic costs of these therapies are staggering. In addition, chronic kidney disease shortens survival and many patients die of diverse causes before reaching end-stage renal disease (1). The pathological substrate of chronic kidney disease is a progressive loss of parenchymal renal cells including glomerular and tubular cells. Apoptosis has been shown to contribute to renal cell loss (2) and it is associated with chronic inflammation and fibrosis. A better understanding of the molecular mechanisms leading to the loss of parenchymal renal cells may identify new targets for therapeutic intervention aimed at slowing the progression of renal disease. Cytokines belonging to the TNF superfamily are key regulators of cell survival, inflammation and fibrosis. Among them, a role for TNF and Fas ligand in the pathogenesis of renal injury has been 
clearly established $(3,4)$. We now review recent data on the involvement of TRAIL, another member of the TNF superfamily, in the pathogenesis of renal injury. We specially centre our attention in diabetic nephropathy (DN), the most common cause of end-stage renal disease.

\section{THE TRAIL/TRAIL-RECEPTOR SYSTEM}

\subsection{The TRAIL cytokine}

TRAIL was originally identified by two independent groups as the third member of the TNF superfamily to induce apoptosis $(5,6)$. TRAIL is a type II trans-membrane protein of 281 and 291 amino acids in the human and murine forms respectively, with an expected molecular mass of 33-35 kDa. Membrane-bound TRAIL can be cleaved from the cell surface to form a soluble trimeric ligand that retains the proapoptotic activity (5). Focus on this cytokine fired up when it was shown that TRAIL can rapidly induce apoptosis in a wide variety of human cancer cell lines and primary tumors, showing minimal or absent toxicity on normal cells $(5,7)$. Currently, TRAIL itself and other TRAIL-receptors (TRAIL-Rs) agonists are in clinical trials as novel anti-cancer therapeutics (for recent reviews on the topic (8-10)).

TRAIL expression is induced on the surface of activated immune cells, such as natural killer cells, T cells, macrophages and dendritic cells (11). Studies with knockout mice for TRAIL and its apoptosis-inducing receptors revealed a main role for TRAIL as an immune effector molecule that mediates anti-tumor cytotoxicity and immune surveillance (summarized in (12)). In agreement with its tumor selective properties, TRAIL is normally expressed in many human tissues including liver, colon, heart, kidney, lung and testis, which suggests that TRAIL must not be cytotoxic to most tissues in vivo under normal physiological conditions $(5,13)$. However, data from knockout mice suggest that TRAIL may induce apoptosis in normal cells immersed in an inflammatory environment (14). Recently, two novel splice variants, TRAIL-alpha and TRAIL-beta, which lack proapoptotic activity, have been described in the human system (15). Thus, regulation of TRAIL-induced apoptosis through alternative splicing in response to cytokine stimulation could also be involved in the fine tuning of the TRAIL system (16).

\subsection{TRAIL receptors}

TRAIL receptors belong to the TNF receptor family. TRAIL binds to a complex system of receptors compared to other members of the TNF superfamily. Five receptors for TRAIL have been described in human; four of them are membrane-bound and one is a soluble receptor. Of the membrane-bound receptors, TRAIL receptor 1 (TRAIL-R1, also APO-2, DR4) and TRAIL receptor 2 (TRAIL-R2, also DR5, TRICK2, KILLER) (17) contain an intact intracellular death domain (DD) which is a prerequisite for apoptosis induction, TRAIL receptor 3 (TRAIL-R3, also DcR1, TRID, LIT) has a glycosylphosphatidylinositol (GPI) membrane anchor and lacks an intracellular domain and TRAIL receptor 4 (TRAIL-R4, also DcR2, TRUNDD) contains a truncated DD. TRAIL-R3 and TRAIL-R4 lack the capacity to induce caspase-dependent apoptosis and are considered to act as decoy receptors. Different mechanisms for inhibiting TRAIL death-signalling by TRAIL-R3 and -R4 have been proposed, including obstruction of proper preassembly of the receptors before ligand binding, competition for ligand binding, and interference with initiator caspases activation and receptor recruitment $(18,19)$. Recent evidence on the biology of TRAIL-R3 and -R4 suggests that they could also be involved in non-apoptotic signalling pathways, which points to a regulatory role for these receptors $(20,21)$. In addition to apoptosis, TRAIL is also able to activate antiapoptotic and proliferative pathways (22). Molecular pathways of apoptosis and survival inducted by the TRAIL/TRAIL-R system will be discussed in detail in the next section.

In addition to its four membrane-bound receptors, there is a fifth TRAIL receptor that lacks cytoplasmic and trans-membrane domains, the soluble decoy osteoprotegerin (OPG, TNFRSF11B)(23). OPG was initially described as a regulator of osteoclastogenesis that binds to the TNF superfamily member receptor activator of NF-kB ligand (RANKL) (24). Binding of RANKL to its receptor RANK induces differentiation, activation and survival of osteoclasts. OPG acts as a soluble inhibitor preventing RANKL/RANK interaction and subsequent osteoclastogenesis. The fact that OPG acts as a decoy for both TRAIL and RANKL opens the door for potential cross-regulatory mechanisms involving the balance among TRAIL, OPG and RANKL. Indeed, OPG binding to TRAIL inhibits TRAIL/TRAIL-Rs interaction and consequently TRAIL-induced apoptosis; while TRAIL can block the inhibitory activity of OPG on osteoclastogenesis (23). In vivo, OPG has been implicated in various skeletal and immune disorders as well as diseases affecting both bone metabolism and immune system, such as rheumatoid arthritis (25-27). Although at physiological temperature, affinity of TRAIL for OPG is weaker as compared to that for its trans-membrane receptors (28); recent studies underlie the biological relevance of the OPG/TRAIL interaction in different in vitro cell systems (29-31).

Due to the extensive use of murine models in research, it is worth mentioning that the murine TRAIL/TRAIL-Rs system displays some differences compared to human (Figure 1). There is only one receptor for TRAIL with a functional DD, TRAIL-R (also MK, mDR5), that is almost equally homologue to human TRAIL-R1 and TRAIL-R2, thus it can not be regarded as the mouse orthologue of one or the other (32). The two other murine TRAIL receptors, mouse decoy $(\mathrm{mDc})$ TRAIL-R1 and TRAILR-2, lack a DD in their cytoplasmic domain and are considered to resemble the decoy functions of human TRAIL-R3 and -R4 (33). However, the overall sequence structure of these receptors is quite different to those of the human decoy TRAIL-Rs, suggesting that the advent of TRAIL decoy receptors is a more recent evolutionary event and points to a benefit in also having non-apoptosis-inducing TRAIL receptors.

\subsection{TRAIL signalling pathways}

Depending on the relative levels of the TRAIL receptors and on the cellular system, TRAIL can exert 


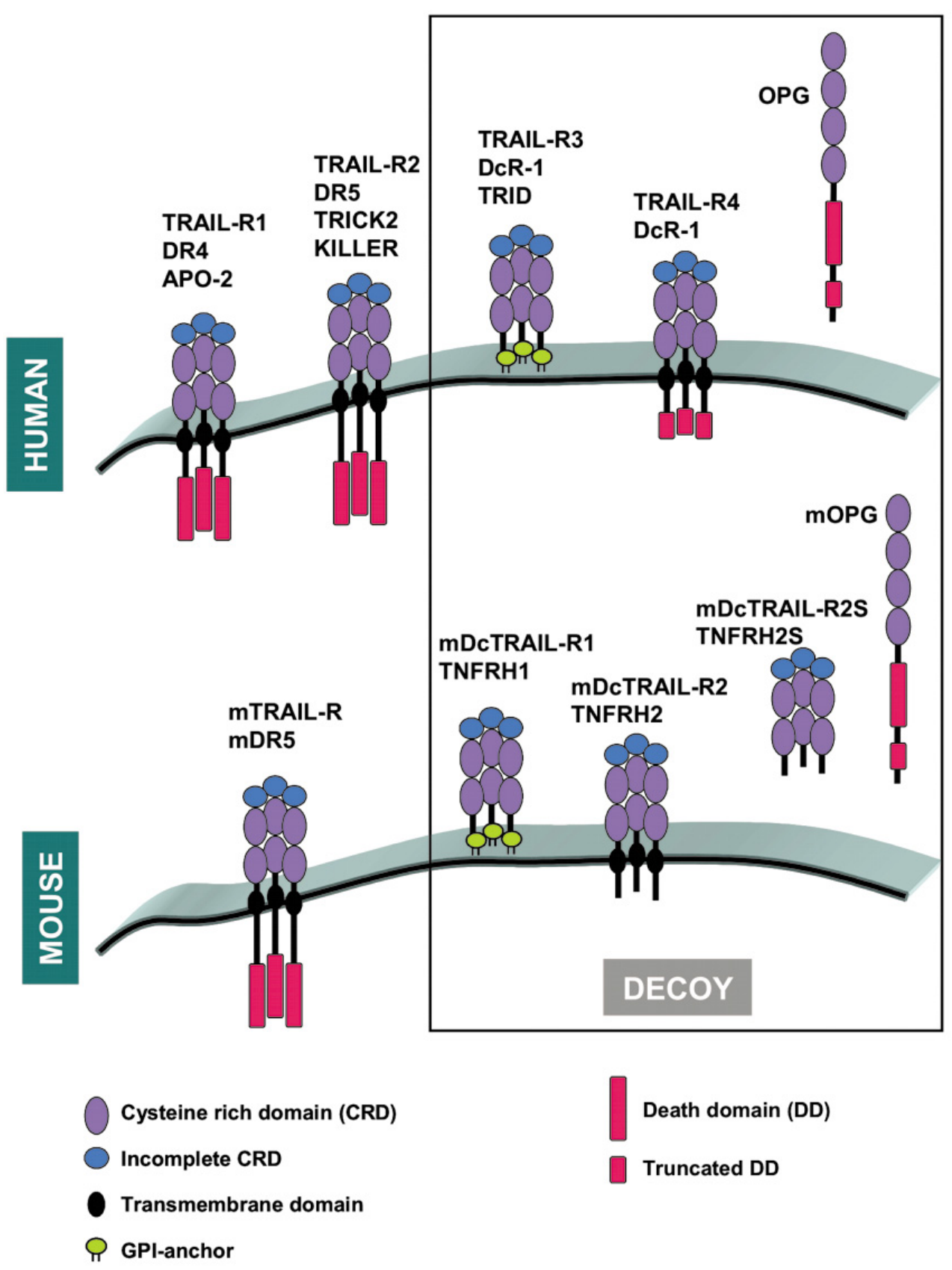

Figure 1. Human and mouse TRAIL receptor system. Human and murine TRAIL receptors overview. The different intracellular and extracellular domains are represented. Cysteine domains are important for ligand binding while death domains are involved in apoptosis induction. Decoy receptors containing truncated or absent DD, Glycosylphosphatidylinositol (GPI)-anchored, or lacking transmembrane domains are squared.

different functions that, in addition to cell death, include cell survival, proliferation and maturation. We will discuss the set of molecules activated upon receptor engagement and their outcome.

TRAIL binding to TRAIL-R1 and -R2 induces their trimerisation and the recruitment of several adaptor proteins and cysteine-dependent aspartate-specific proteases (caspases) to form a receptor complex named the death-inducing signalling complex (DISC). The first protein recruited to the DISC is the intracellular adaptor protein Fas-associated death domain (FADD, also Mort1) via its DD. In addition to a DD, FADD contains a death effector domain (DED) that binds to the DED of procaspase- 8 or -10 (34). Caspases are synthesised as inactive pro-enzymes and recruitment to the DISC induces their activation. Depending on the cell type or cell status, active caspase- 8 can induce cell death via the so called "extrinsic 


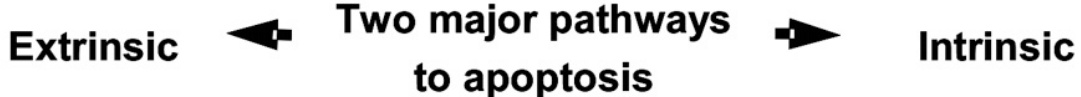

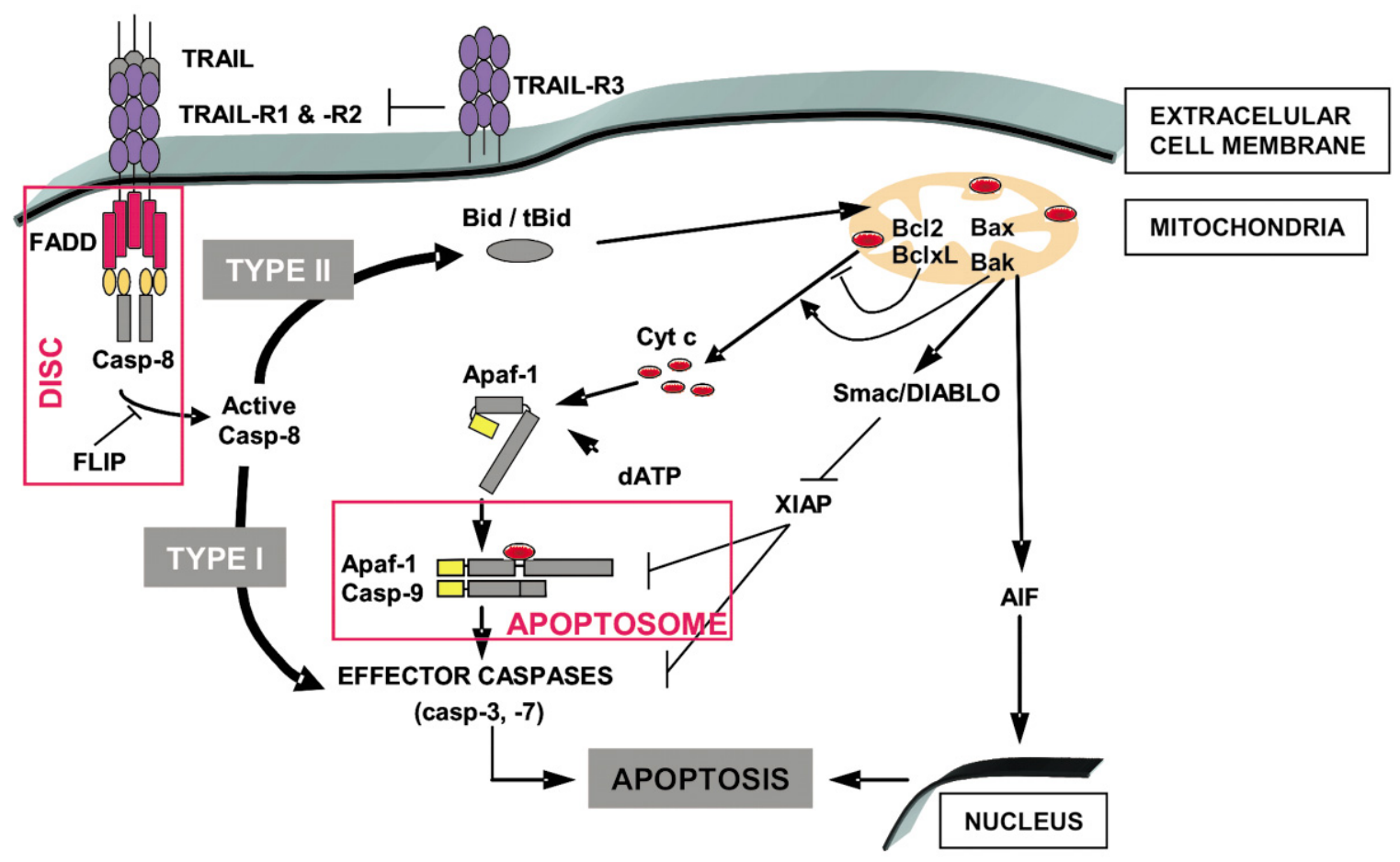

Cysteine rich domain (CRD)

Death effector domain (DED)

Death domain (DD)

$\square$ Caspase recruitment domain (CARD)

Figure 2. Classical apoptotic pathways triggered by functional dead domain-containing TRAIL receptors. Upon TRAIL-R oligomerisation the adaptor molecule FADD and the pro-form of caspase- 8 are sequentially recruited to the intracellular potion of the receptor via DD and DED interactions. The regulator c-FLIP can also be recruited to this complex named death-inducing signalling complex (DISC). The resulting oligomerisation of procaspase- 8 results in its autoproteolytic processing and activation. The ensuing apoptotic program kills cells via two different pathways: either active caspase- 8 directly cleaves and activates caspase-3 (type I) or caspase-3 cleavage is induced indirectly through cleavage of Bid and activation of the mitochondrial pathway (type II).

pathway" that involves direct cleavage and activation of the downstream effectors caspase-3 and -7 ; or may require amplification of the death signal via the "intrinsic pathway" through the cleavage of the pro-apoptotic Bcl-2 family member Bid (2)(Figure 2). Truncated Bid (tBid) moves to the outer mitochondrial membrane where it is thought to neutralise the anti-apoptotic Bcl-2 family members (Bcl-2 and $\mathrm{Bcl}-\mathrm{xL}$ ) and to collaborate with pro-apoptotic $\mathrm{Bcl}-2$ family members (Bax, Bak), promoting the release of cytochrome $\mathrm{c}$ from the mitochondrial intermembrane space to the cytosol $(35,36)$. In the cytosol, released cytochrome $\mathrm{c}$ binds to the adaptor molecule Apaf-t to form the so-called apoptosome that mediates the activation of caspase- 9 and the subsequent cleavage of caspase-3. Other proteins released from mitochondria can promote cell death; it is the case of Smac/Diablo, that interacts with the X-linked inhibitor of apoptosis (XIAP) interfering with its binding to caspase- 3 and -7 , and thus allowing the full activation of these effector caspases (37-39). Apoptosis inducing factor
(AIF) is released from the activated mitochondria and travels to the cell nucleus inducing DNA fragmentation and cell death (40).

TRAIL receptor signalling does not necessarily lead to the activation of effector caspases and subsequent cell death. TRAIL can also signal development or proliferation through the activation of NF-kB, PKB/Akt and MAPK. However, compared to the apoptosis-inducing molecular mechanisms triggered by TRAIL, non-apoptotic TRAIL dependent pathways are poorly understood. TRAIL can activate NF-kB through TRAIL-R1, TRAIL-R2, and, interestingly, through TRAIL-R4 (41-43). The adaptor protein receptor-interacting protein (RIP) has been detected in the TRAIL DISC (44) and it has been shown to be involved in TRAIL-induced NF-kB activation (45). RIP is recruited to the TNF/TNF-receptor complex via its DD through the adaptor protein TNF receptor 1 associated death domain protein (TRADD), here RIP recruits several 
signalling proteins, including TRAF2, that is essential for the recruitment and activation of the IKK complex. When activated, this complex phosphorylates inhibitors of $\mathrm{kB}$ (IkB), leading to IkB degradation and NF-kB activation. In the context of TRAIL, RIP also interacts with FADD and a possible role for TRAF2 in TRAIL-induced NF-kB activation has been suggested (46), though not completely confirmed (45). It is difficult to delineate the actual role of NF-kB in TRAIL-mediated signalling due to the pleiotropic effects induced by this transcription factor. In this context, it seems that: i) in cells sensitive to TRAIL-induced apoptosis the ability of TRAIL to activate NF-kB is ineffective in protecting from cell death, though preactivation of NF-kB can confer resistance to TRAILmediated apoptosis; ii) in TRAIL-resistant cells, the predominant signal emanating from TRAIL-Rs would be the activation of NF-kB, and silencing of NF-kB in these cells may not sensitise to TRAIL-induced apoptosis (47, 48). Expression of the anti-apoptotic factors Bcl-xL, cFLIP and XIAP has been implicated in NF-kB mediated survival against TRAIL $(47,49,50)$.

Also, TRAIL has been shown to activate the protein kinase B (PKB)/Akt and the MAPK/ERK pathways (for a review (22)), though the precise molecular mechanisms that link TRAIL-receptor cross-linking to kinase activation are not fully elucidated. The c-Jun NH2terminal kinase (JNK) belongs to the MAPK family and can be recruited to the TNF receptor-DISC via TRADDRIP-TRAF2 interaction. JNK activation in response to TRAIL induces death of target cells. However, it is still controversial whether TRAIL-induced JNK activation requires RIP and TRAF2 or involves a different signalling pathway $(45,51)$. TRAIL-induced ERK and Akt activation is mainly associated with an anti-apoptotic function that could involve inhibition of caspase-8, processing of Bid (52), and blocking the release of the proapoptotic factor Smac/DIABLO from mitochondria (53). Both, PKB/Akt and MAPK/ERK pathways have been involved in the survival and proliferation of different cell types $(54,55)$. In particular TRAIL-induced PKB/Akt activation plays a central role in vascular cell biology $(56,57)$.

\section{EXPRESSION OF TRAIL AND ITS RECEPTORS IN THE KIDNEY}

\subsection{Healthy kidney}

Early studies detected TRAIL, TRAIL-R1 and $-R 2$ mRNA expression in the kidney $(5,17)$. Immunohistochemistry studies revealed that TRAIL is expressed only in the tubuli but not in the glomeruli of the normal kidney (13). TRAIL-R1 has a similar pattern of expression to TRAIL, while TRAIL-R2 is additionally expressed in the Henle's loop (13). TRAIL-R3 expression was not detected in the normal kidney (13) and there are no reports regarding renal expression of TRAIL-R4. No kidney pathology has been reported in TRAIL knockout mice, suggesting that TRAIL is not required for normal kidney development and physiology (58). By contrast, OPG deficient mice display calcification of the aorta and renal arteries (59), suggesting that besides its well-known role in bone homeostasis, regulation of OPG may play a role in vascular calcification.

\subsection{Diseased kidney}

Differential expression of TRAIL and its receptors has been reported in kidney injury and renal tumors. However, studies in cultured renal cells are scarce and functional in vivo studies are lacking.

Diabetic nephropathy (DN) is the most common cause of end-stage renal disease and many of the concepts on the pathogenesis and treatment of renal disease have first been elucidated in this form of renal injury. Recent data on microarray analysis of human DN kidney samples showed that TRAIL expression is increased in DN patients and correlates to parameters of kidney injury, such as tubular atrophy (60). Interestingly, immunohistochemistry of kidney tissue showed de novo TRAIL expression in the glomeruli of the DN samples and increased tubular staining (60). While the increment in tubulointerstitial TRAIL expression is not specific for DN and it is observed in other human kidney diseases, cell culture studies suggest that the diabetic kidney may be particularly sensitive to the actions of TRAIL. Proinflammatory cytokines, which are expected to be present in any form of chronic kidney disease, induce TRAIL expression in tubular cells. In addition, a high glucose medium, characteristic of diabetes, sensitised tubular cells to the proapoptotic effect of TRAIL (60). Thus, increased TRAIL expression could contribute to kidney injury through the induction of apoptosis that takes place in the course of DN (61)(Figure 3). The level of apoptosis induction achieved by TRAIL in cultured tubular cells is consistent with the loss of renal function over years that characterises DN. In autoimmune diseases, TRAIL is mostly involved in preventing disease progression by inhibiting the auto reactive immune response. Blockage of TRAIL in murine models of autoimmune diabetes (type I diabetes) led to an increased incidence and severity of disease (62-64). Thus, depending on the type of diabetes and on the disease stage, TRAIL can have a dual role either as an immune modulator or as a regulatory molecule of tubular and vascular cell survival.

Renal transplantation is the best treatment of some end-stage renal diseases. The major problem associated is rejection or dysfunction of the transplanted kidney. Many cytokines participate in rejection by inducing inflammation or apoptosis. In this sense, TRAIL, TRAIL$\mathrm{R} 1$ and -R2, have been found to be strongly expressed in renal proximal and distal convoluted tubules of rejected kidney tissue. Also, serum soluble TRAIL level in renal transplant patients was significantly higher than that in healthy donors (65). Consistently with its role in tumor surveillance, TRAIL expression has been found to be lower in renal tumors with poor prognosis than in normal kidney. Also, TRAIL-R1 expression is higher in good prognosis tumors (66).

Research on the role of TRAIL/TRAIL-Rs in kidney diseases is at its beginning; yet, evidence points to a role of this system in renal cancer and kidney inflammatory and autoimmune diseases. 


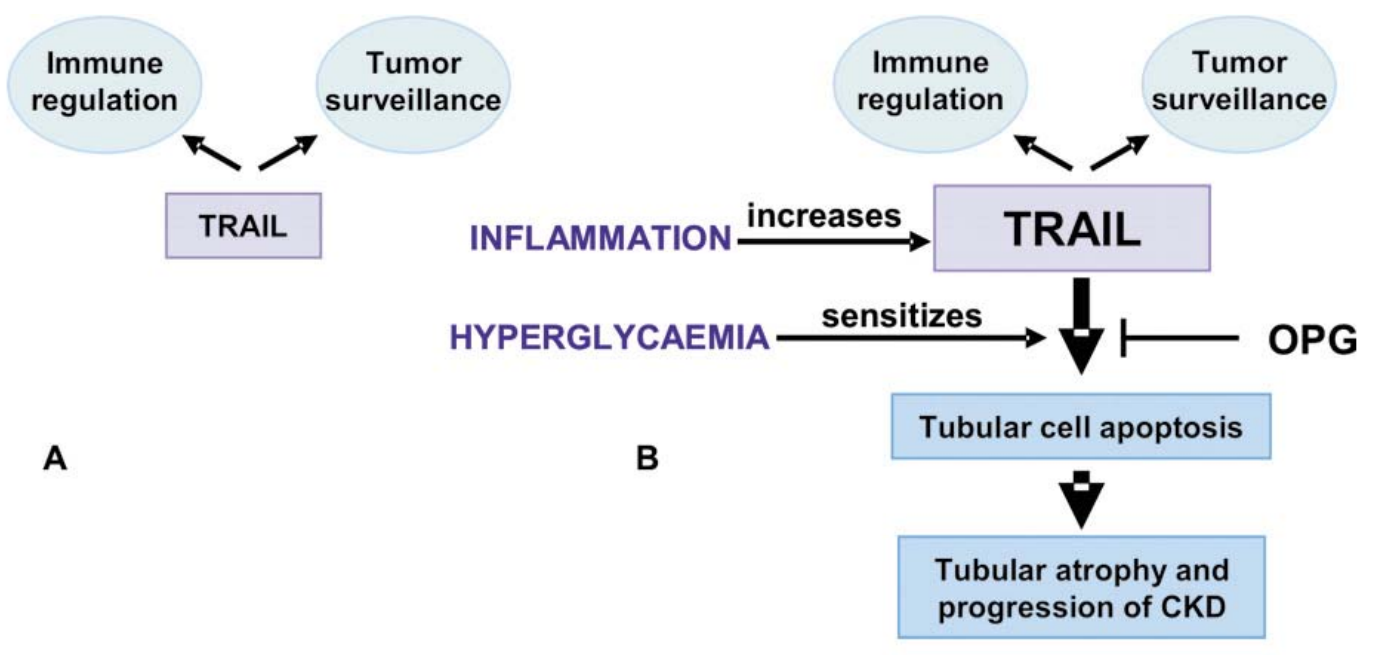

Figure 3. Model proposed for the role and regulation of TRAIL in tubular cell apoptosis in diabetic nephropathy. A) Normal kidney. Basal tubular cell TRAIL expression may have housekeeping functions regarding modulation of the immune response and tumor surveillance. B) In diabetic kidney inflammatory cytokines increase TRAIL expression and hyperglycaemia sensitises to tubular cell death induced by TRAIL. The result may be the abnormal loss of parenchymal tubular epithelial cells. An increased expression of OPG may help counteract the adverse consequences of the presence of high amounts of TRAIL. CKD: chronic kidney disease.

\subsection{OPG: friend or foe?}

OPG is a decoy receptor for both TRAIL and RANKL, suggesting a potential role as integrator of the actions of both cytokines. OPG levels are increased in serum of patients with renal dysfunction (67-69), including DN (70, 71). Increased OPG serum levels are also associated to increased coronary artery and aorta calcification and behave as independent predictor of cardiovascular death in renal transplant recipients, raising concerns of a deleterious effect of OPG $(67-70,72)$. It has been proposed that increased OPG may contribute to endothelial dysfunction, based on cell culture studies that showed interference with actions of RANKL (73). By contrast, OPG protects insulin-producing cells from apoptosis (74). A local increment of renal OPG has also been identified in kidneys from patients with chronic renal injury (60). OPG interferes with TRAIL-induced actions on cultured renal tubular cells and improves cell survival, suggesting that the interplay between TRAIL and OPG might be one of the pathways for OPG to modulate diabetic tissue injury (60). The contribution of OPG in vivo will probably depend on the relative local tissue levels of both molecules in the cell microenvironment, as it is the case for other cytokine/soluble receptor systems. As an example both TNF $\alpha$ and soluble TNF receptor levels are increased in serum and synovial fluid in patients with rheumatoid arthritis $(60,75)$ and inhibiting $\mathrm{TNF} \alpha$ activity in this disease by soluble TNF receptors has been remarkably successful (76).

The definitive answer on the in vivo role of OPG in kidney injury is likely to come from clinical trials. Specific clinical trials for OPG on kidney injury cannot be launched based on the currently available evidence; however, careful monitoring of renal function in diabetic individuals treated with OPG for osteoporosis could offer early insights into possible effects of the protein on renal function in vivo. This early promising phase I clinical trials for the treatment of osteoporosis, suggested that different forms of recombinant OPG had beneficial effects on bone resorption and were well tolerated $(77,78)$, and opened the way for further clinical trials with OPG, including diabetesassociated bone loss. Unfortunately, the superiority of an anti-RANKL antibody (AMG 162, denosumab) in bone protection, as well as concerns over the potential development of anti-OPG antibodies or interference with the tumor surveillance role of TRAIL have ended any further OPG clinical trials on bone (reviewed in (79)).

\section{PERSPECTIVES}

There is recent but scarce information on the role of TRAIL and OPG in kidney. Descriptive human data have localized an increased expression of TRAIL and OPG in the diabetic kidney and other chronic kidney diseases. Cell culture data point to a role of TRAIL in regulating tubular cell death, in cooperation with cytokines and glucose from the cell microenvironment. Interventional in vivo studies would be needed to define more clearly the therapeutic potential of TRAIL activity modulation. Unfortunately, an opportunity to obtain human data has been lost when clinical trials using OPG for the treatment of osteoporosis were abandoned, so studies involving animal models of disease will be helpful.

\section{REFERENCES}

1. M. Tonelli, N. Wiebe, B. Culleton, A. House, C. Rabbat, M. Fok, F. McAlister and A. X. Garg: isease and rtality risk: a systematic review. J Am Soc Nephrol, 17(7), 2034-47 (2006) orz, A. Benito-Martin, P. Justo, A. B. Sanz, M. D. Sanchez-Nino, B. Santamaria, J. Egido and A. Ortiz: 
Modulation of renal tubular cell survival: where is the evidence? Curr Med Chem, 13(4), 449-54 (2006)

3. A. Ortiz, C. Lorz and J. Egido: New kids in the block: the role of FasL and Fas in kidney damage. $J$ Nephrol, 12(3), 150-8 (1999)

4. J. F. Navarro and C. Mora-Fernandez: The role of TNFalpha in diabetic nephropathy: pathogenic and therapeutic implications. Cytokine Growth Factor Rev, 17(6), 441-50 (2006)

5. S. R. Wiley, K. Schooley, P. J. Smolak, W. S. Din, C. P. Huang, J. K. Nicholl, G. R. Sutherland, T. D. Smith, C. Rauch, C. A. Smith and et al.: Identification and characterization of a new member of the TNF family that induces apoptosis. Immunity, 3(6), 673-82 (1995)

6. R. M. Pitti, S. A. Marsters, S. Ruppert, C. J. Donahue, A. Moore and A. Ashkenazi: Induction of apoptosis by Apo-2 ligand, a new member of the tumor necrosis factor cytokine family. J Biol Chem, 271(22), 12687-90 (1996)

7. H. Walczak, R. E. Miller, K. Ariail, B. Gliniak, T. S. Griffith, M. Kubin, W. Chin, J. Jones, A. Woodward, T. Le, C. Smith, P. Smolak, R. G. Goodwin, C. T. Rauch, J. C. Schuh and D. H. Lynch: Tumoricidal activity of tumor necrosis factor-related apoptosis-inducing ligand in vivo. Nat Med, 5(2), 157-63 (1999)

8. K. Takeda, J. Stagg, H. Yagita, K. Okumura and M. J. Smyth: Targeting death-inducing receptors in cancer therapy. Oncogene, 26(25), 3745-57 (2007)

9. M. A. Hall and J. L. Cleveland: Clearing the TRAIL for Cancer Therapy. Cancer Cell, 12(1), 4-6 (2007)

10. C. Carlo-Stella, C. Lavazza, A. Locatelli, L. Vigano, A. M. Gianni and L. Gianni: Targeting TRAIL agonistic receptors for cancer therapy. Clin Cancer Res, 13(8), 23137 (2007)

11. A. Anel, A. Bosque, J. Naval, A. Pineiro, L. Larrad, M. A. Alava and M. J. Martinez-Lorenzo: Apo2L/TRAIL and immune regulation. Front Biosci, 12, 2074-84 (2007)

12. U. Schaefer, O. Voloshanenko, D. Willen and H. Walczak: TRAIL: a multifunctional cytokine. Front Biosci, 12, 3813-24 (2007)

13. D. C. Spierings, E. G. de Vries, E. Vellenga, F. A. van den Heuvel, J. J. Koornstra, J. Wesseling, H. Hollema and S. de Jong: Tissue distribution of the death ligand TRAIL and its receptors. $J$ Histochem Cytochem, 52(6), 821-31 (2004)

14. S. J. Zheng, P. Wang, G. Tsabary and Y. H. Chen: Critical roles of TRAIL in hepatic cell death and hepatic inflammation. J Clin Invest, 113(1), 58-64 (2004)

15. A. Krieg, T. Krieg, M. Wenzel, M. Schmitt, U. Ramp, B. Fang, H. E. Gabbert, C. D. Gerharz and C. Mahotka:
TRAIL-beta and TRAIL-gamma: two novel splice variants of the human TNF-related apoptosis-inducing ligand (TRAIL) without apoptotic potential. Br J Cancer, 88(6), 918-27 (2003)

16. M. Kamachi, T. Aramaki, S. Tanimura, K. Ichinose, K. Fujikawa, N. Iwamoto, A. Yoshizaki, H. Ida, A. Kawakami, M. Kohno and K. Eguchi: Activation of protein phosphatase causes alternative splicing of tumor necrosis factor-related apoptosis-inducing ligand (TRAIL): potential effect on immune surveillance. Biochem Biophys Res Commun, 360(1), 280-5 (2007)

17. M. MacFarlane, M. Ahmad, S. M. Srinivasula, T. Fernandes-Alnemri, G. M. Cohen and E. S. Alnemri: Identification and molecular cloning of two novel receptors for the cytotoxic ligand TRAIL. J Biol Chem, 272(41), 25417-20 (1997)

18. L. Clancy, K. Mruk, K. Archer, M. Woelfel, J. Mongkolsapaya, G. Screaton, M. J. Lenardo and F. K. Chan: Preligand assembly domain-mediated ligandindependent association between TRAIL receptor 4 (TR4) and TR2 regulates TRAIL-induced apoptosis. Proc Natl Acad Sci U S A, 102(50), 18099-104 (2005)

19. D. Merino, N. Lalaoui, A. Morizot, P. Schneider, E. Solary and O. Micheau: Differential inhibition of TRAILmediated DR5-DISC formation by decoy receptors 1 and 2 . Mol Cell Biol, 26(19), 7046-55 (2006)

20. X. D. Zhang, A. V. Franco, T. Nguyen, C. P. Gray and P. Hersey: Differential localization and regulation of death and decoy receptors for TNF-related apoptosis-inducing ligand (TRAIL) in human melanoma cells. J Immunol, 164(8), 3961-70 (2000)

21. E. Rimondi, P. Secchiero, A. Quaroni, C. Zerbinati, S. Capitani and G. Zauli: Involvement of TRAIL/TRAILreceptors in human intestinal cell differentiation. $J$ Cell Physiol, 206(3), 647-54 (2006)

22. C. Falschlehner, C. H. Emmerich, B. Gerlach and H. Walczak: TRAIL signalling: Decisions between life and death. Int J Biochem Cell Biol, 39(7-8), 1462-75 (2007)

23. J. G. Emery, P. McDonnell, M. B. Burke, K. C. Deen, S. Lyn, C. Silverman, E. Dul, E. R. Appelbaum, C. Eichman, R. DiPrinzio, R. A. Dodds, I. E. James, M. Rosenberg, J. C. Lee and P. R. Young: Osteoprotegerin is a receptor for the cytotoxic ligand TRAIL. J Biol Chem, 273(23), 14363-7 (1998)

24. W. S. Simonet, D. L. Lacey, C. R. Dunstan, M. Kelley, M. S. Chang, R. Luthy, H. Q. Nguyen, S. Wooden, L. Bennett, T. Boone, G. Shimamoto, M. DeRose, R. Elliott, A. Colombero, H. L. Tan, G. Trail, J. Sullivan, E. Davy, N. Bucay, L. Renshaw-Gegg, T. M. Hughes, D. Hill, W. Pattison, P. Campbell, S. Sander, G. Van, J. Tarpley, P. Derby, R. Lee and W. J. Boyle: Osteoprotegerin: a novel secreted protein involved in the regulation of bone density. Cell, 89(2), 309-19 (1997) 
25. T. Cundy, M. Hegde, D. Naot, B. Chong, A. King, R. Wallace, J. Mulley, D. R. Love, J. Seidel, M. Fawkner, T. Banovic, K. E. Callon, A. B. Grey, I. R. Reid, C. A. Middleton-Hardie and J. Cornish: A mutation in the gene TNFRSF11B encoding osteoprotegerin causes an idiopathic hyperphosphatasia phenotype. Hum Mol Genet, 11(18), 2119-27 (2002)

26. C. M. Shipman and P. I. Croucher: Osteoprotegerin is a soluble decoy receptor for tumor necrosis factor-related apoptosis-inducing ligand/Apo2 ligand and can function as a paracrine survival factor for human myeloma cells. Cancer Res, 63(5), 912-6 (2003)

27. N. C. Walsh, T. N. Crotti, S. R. Goldring and E. M. Gravallese: Rheumatic diseases: the effects of inflammation on bone. Immunol Rev, 208, 228-51 (2005)

28. A. Truneh, S. Sharma, C. Silverman, S. Khandekar, M. P. Reddy, K. C. Deen, M. M. McLaughlin, S. M. Srinivasula, G. P. Livi, L. A. Marshall, E. S. Alnemri, W. V. Williams and M. L. Doyle: Temperature-sensitive differential affinity of TRAIL for its receptors. DR5 is the highest affinity receptor. J Biol Chem, 275(30), 23319-25 (2000)

29. T. Miyashita, A. Kawakami, T. Nakashima, S. Yamasaki, M. Tamai, F. Tanaka, M. Kamachi, H. Ida, K. Migita, T. Origuchi, K. Nakao and K. Eguchi: Osteoprotegerin (OPG) acts as an endogenous decoy receptor in tumour necrosis factor-related apoptosisinducing ligand (TRAIL)-mediated apoptosis of fibroblastlike synovial cells. Clin Exp Immunol, 137(2), 430-6 (2004)

30. L. B. Pritzker, M. Scatena and C. M. Giachelli: The role of osteoprotegerin and tumor necrosis factor-related apoptosis-inducing ligand in human microvascular endothelial cell survival. Mol Biol Cell, 15(6), 2834-41 (2004)

31. I. Holen, P. I. Croucher, F. C. Hamdy and C. L. Eaton: Osteoprotegerin (OPG) is a survival factor for human prostate cancer cells. Cancer Res, 62(6), 1619-23 (2002)

32. G. S. Wu, T. F. Burns, Y. Zhan, E. S. Alnemri and W. S. El-Deiry: Molecular cloning and functional analysis of the mouse homologue of the KILLER/DR5 tumor necrosis factor-related apoptosis-inducing ligand (TRAIL) death receptor. Cancer Res, 59(12), 2770-5 (1999)

33. P. Schneider, D. Olson, A. Tardivel, B. Browning, A. Lugovskoy, D. Gong, M. Dobles, S. Hertig, K. Hofmann, H. Van Vlijmen, Y. M. Hsu, L. C. Burkly, J. Tschopp and T. S. Zheng: Identification of a new murine tumor necrosis factor receptor locus that contains two novel murine receptors for tumor necrosis factor-related apoptosis-inducing ligand (TRAIL). J Biol Chem, 278(7), 5444-54 (2003)

34. M. R. Sprick, M. A. Weigand, E. Rieser, C. T. Rauch, P. Juo, J. Blenis, P. H. Krammer and H. Walczak: FADD/MORT1 and caspase- 8 are recruited to TRAIL receptors 1 and 2 and are essential for apoptosis mediated by TRAIL receptor 2. Immunity, 12(6), 599-609 (2000)

35. H. Li, H. Zhu, C. J. Xu and J. Yuan: Cleavage of BID by caspase 8 mediates the mitochondrial damage in the Fas pathway of apoptosis. Cell, 94(4), 491-501 (1998)

36. X. Luo, I. Budihardjo, H. Zou, C. Slaughter and X. Wang: Bid, a $\mathrm{Bcl} 2$ interacting protein, mediates cytochrome $\mathrm{c}$ release from mitochondria in response to activation of cell surface death receptors. Cell, 94(4), 48190 (1998)

37. P. Justo, A. Sanz, C. Lorz, D. Gomez-Garre, S. Mezzano, J. Egido and A. Ortiz: Expression of Smac/Diablo in tubular epithelial cells and during acute renal failure. Kidney Int Suppl(86), S52-6 (2003)

38. A. M. Verhagen, P. G. Ekert, M. Pakusch, J. Silke, L. M. Connolly, G. E. Reid, R. L. Moritz, R. J. Simpson and D. L. Vaux: Identification of DIABLO, a mammalian protein that promotes apoptosis by binding to and antagonizing IAP proteins. Cell, 102(1), 43-53 (2000)

39. C. Du, M. Fang, Y. Li, L. Li and X. Wang: Smac, a mitochondrial protein that promotes cytochrome cdependent caspase activation by eliminating IAP inhibition. Cell, 102(1), 33-42 (2000)

40. H. K. Lorenzo, S. A. Susin, J. Penninger and G. Kroemer: Apoptosis inducing factor (AIF): a phylogenetically old, caspase-independent effector of cell death. Cell Death Differ, 6(6), 516-24 (1999)

41. P. Schneider, M. Thome, K. Burns, J. L. Bodmer, K. Hofmann, T. Kataoka, N. Holler and J. Tschopp: TRAIL receptors 1 (DR4) and 2 (DR5) signal FADD-dependent apoptosis and activate NF-kappaB. Immunity, 7(6), 831-6 (1997)

42. P. M. Chaudhary, M. Eby, A. Jasmin, A. Bookwalter, J. Murray and L. Hood: Death receptor 5, a new member of the TNFR family, and DR4 induce FADD-dependent apoptosis and activate the NF-kappaB pathway. Immunity, 7(6), 821-30 (1997)

43. M. A. Degli-Esposti, W. C. Dougall, P. J. Smolak, J. Y. Waugh, C. A. Smith and R. G. Goodwin: The novel receptor TRAIL-R4 induces NF-kappaB and protects against TRAIL-mediated apoptosis, yet retains an incomplete death domain. Immunity, 7(6), 813-20 (1997)

44. N. Harper, S. N. Farrow, A. Kaptein, G. M. Cohen and M. MacFarlane: Modulation of tumor necrosis factor apoptosis-inducing ligand- induced NF-kappa B activation by inhibition of apical caspases. J Biol Chem, 276(37), 34743-52 (2001)

45. Y. Lin, A. Devin, A. Cook, M. M. Keane, M. Kelliher, S. Lipkowitz and Z. G. Liu: The death domain kinase RIP is essential for TRAIL (Apo2L)-induced activation of 
IkappaB kinase and c-Jun N-terminal kinase. Mol Cell Biol, 20(18), 6638-45 (2000)

46. W. H. Hu, H. Johnson and H. B. Shu: Tumor necrosis factor-related apoptosis-inducing ligand receptors signal NF-kappaB and JNK activation and apoptosis through distinct pathways. J Biol Chem, 274(43), 30603-10 (1999)

47. S. J. Braeuer, C. Buneker, A. Mohr and R. M. Zwacka: Constitutively activated nuclear factor-kappaB, but not induced NF-kappaB, leads to TRAIL resistance by upregulation of $\mathrm{X}$-linked inhibitor of apoptosis protein in human cancer cells. Mol Cancer Res, 4(10), 715-28 (2006)

48. H. Ehrhardt, S. Fulda, I. Schmid, J. Hiscott, K. M. Debatin and I. Jeremias: TRAIL induced survival and proliferation in cancer cells resistant towards TRAILinduced apoptosis mediated by NF-kappaB. Oncogene, 22(25), 3842-52 (2003)

49. L. Zender, S. Hutker, B. Mundt, M. Waltemathe, C. Klein, C. Trautwein, N. P. Malek, M. P. Manns, F. Kuhnel and S. Kubicka: NFkappaB-mediated upregulation of bcl-xl restrains TRAIL-mediated apoptosis in murine viral hepatitis. Hepatology, 41(2), 280-8 (2005)

50. R. Bortul, P. L. Tazzari, A. Cappellini, G. Tabellini, A. M. Billi, R. Bareggi, L. Manzoli, L. Cocco and A. M. Martelli: Constitutively active Akt1 protects HL60 leukemia cells from TRAIL-induced apoptosis through a mechanism involving NF-kappaB activation and cFLIP(L) up-regulation. Leukemia, 17(2), 379-89 (2003)

51. E. Varfolomeev, H. Maecker, D. Sharp, D. Lawrence, M. Renz, D. Vucic and A. Ashkenazi: Molecular determinants of kinase pathway activation by Apo2 ligand/tumor necrosis factor-related apoptosis-inducing ligand. J Biol Chem, 280(49), 40599-608 (2005)

52. T. S. Soderstrom, M. Poukkula, T. H. Holmstrom, K. M. Heiskanen and J. E. Eriksson: Mitogen-activated protein kinase/extracellular signal-regulated kinase signaling in activated $\mathrm{T}$ cells abrogates TRAIL-induced apoptosis upstream of the mitochondrial amplification loop and caspase-8. J Immunol, 169(6), 2851-60 (2002)

53. X. D. Zhang, J. M. Borrow, X. Y. Zhang, T. Nguyen and P. Hersey: Activation of ERK1/2 protects melanoma cells from TRAIL-induced apoptosis by inhibiting Smac/DIABLO release from mitochondria. Oncogene, 22(19), 2869-81 (2003)

54. T. J. Lee, J. T. Lee, J. W. Park and T. K. Kwon: Acquired TRAIL resistance in human breast cancer cells are caused by the sustained cFLIP(L) and XIAP protein levels and ERK activation. Biochem Biophys Res Commun, 351(4), 1024-30 (2006)

55. P. Secchiero, E. Melloni, M. Heikinheimo, S. Mannisto, R. Di Pietro, A. Iacone and G. Zauli: TRAIL regulates normal erythroid maturation through an ERK-dependent pathway. Blood, 103(2), 517-22 (2004)
56. P. Secchiero, C. Zerbinati, E. Rimondi, F. Corallini, D. Milani, V. Grill, G. Forti, S. Capitani and G. Zauli: TRAIL promotes the survival, migration and proliferation of vascular smooth muscle cells. Cell Mol Life Sci, 61(15), 1965-74 (2004)

57. P. Secchiero, A. Gonelli, E. Carnevale, D. Milani, A. Pandolfi, D. Zella and G. Zauli: TRAIL promotes the survival and proliferation of primary human vascular endothelial cells by activating the Akt and ERK pathways. Circulation, 107(17), 2250-6 (2003)

58. E. Cretney, K. Takeda, H. Yagita, M. Glaccum, J. J. Peschon and M. J. Smyth: Increased susceptibility to tumor initiation and metastasis in TNF-related apoptosis-inducing ligand-deficient mice. J Immunol, 168(3), 1356-61 (2002)

59. N. Bucay, I. Sarosi, C. R. Dunstan, S. Morony, J. Tarpley, C. Capparelli, S. Scully, H. L. Tan, W. Xu, D. L. Lacey, W. J. Boyle and W. S. Simonet: osteoprotegerindeficient mice develop early onset osteoporosis and arterial calcification. Genes Dev, 12(9), 1260-8 (1998)

60. C. Lorz, A. Benito-Martin, A. Boucherot, A. C. Ucero, M. P. Rastaldi, A. Henger, S. Armelloni, B. Santamaria, C. C. Berthier, M. Kretzler, J. Egido and A. Ortiz: The Death Ligand TRAIL in Diabetic Nephropathy. J Am Soc Nephrol (2008)

61. D. Kumar, S. Robertson and K. D. Burns: Evidence of apoptosis in human diabetic kidney. Mol Cell Biochem, 259(12), 67-70 (2004)

62. S. E. Lamhamedi-Cherradi, S. Zheng, R. M. Tisch and Y. H. Chen: Critical roles of tumor necrosis factor-related apoptosis-inducing ligand in type 1 diabetes. Diabetes, 52(9), 2274-8 (2003)

63. Q. S. Mi, D. Ly, S. E. Lamhamedi-Cherradi, K. V. Salojin, L. Zhou, M. Grattan, C. Meagher, P. Zucker, Y. H. Chen, J. Nagle, D. Taub and T. L. Delovitch: Blockade of tumor necrosis factor-related apoptosis-inducing ligand exacerbates type 1 diabetes in NOD mice. Diabetes, 52(8), 1967-75 (2003)

64. S. E. Lamhamedi-Cherradi, S. J. Zheng, K. A. Maguschak, J. Peschon and Y. H. Chen: Defective thymocyte apoptosis and accelerated autoimmune diseases in TRAIL-/- mice. Nat Immunol, 4(3), 255-60 (2003)

65. C. J. Song, X. S. Liu, Y. Zhu, L. H. Chen, W. Jia, Y. N. Li, Y. X. Cao, X. Xie, R. Zhuang, C. S. Zhu and B. Q. Jin: Expression of TRAIL, DR4, and DR5 in kidney and serum from patients receiving renal transplantation. Transplant Proc, 36(5), 1340-3 (2004)

66. S. Takamizawa, S. Okamoto, W. Bishop, J. Wen, K. Kimura and A. Sandler: Differential apoptosis gene expression in pediatric tumors of the kidney. J Pediatr Surg, 35(2), 390-5 (2000)

67. K. Nitta, T. Akiba, K. Uchida, A. Kawashima, W. Yumura, T. Kabaya and H. Nihei: The progression of vascular calcification and serum osteoprotegerin levels in 
patients on long-term hemodialysis. Am J Kidney Dis, 42(2), 303-9 (2003)

68. I. Avbersek-Luznik, I. Malesic, I. Rus and J. Marc: Increased levels of osteoprotegerin in hemodialysis patients. Clin Chem Lab Med, 40(10), 1019-23 (2002)

69. J. J. Kazama, T. Shigematsu, K. Yano, E. Tsuda, M. Miura, Y. Iwasaki, Y. Kawaguchi, F. Gejyo, K. Kurokawa and M. Fukagawa: Increased circulating levels of osteoclastogenesis inhibitory factor (osteoprotegerin) in patients with chronic renal failure. Am J Kidney Dis, 39(3), 525-32 (2002)

70. L. M. Rasmussen, L. Tarnow, T. K. Hansen, H. H. Parving and A. Flyvbjerg: Plasma osteoprotegerin levels are associated with glycaemic status, systolic blood pressure, kidney function and cardiovascular morbidity in type 1 diabetic patients. Eur $J$ Endocrinol, 154(1), 75-81 (2006)

71. S. Doi, N. Yorioka, T. Masaki, T. Ito, K. Shigemoto and S. Harada: Increased serum osteoprotegerin level in older and diabetic hemodialysis patients. Ther Apher Dial, 8(4), 335-9 (2004)

72. J. Hjelmesaeth, T. Ueland, A. Flyvbjerg, J. Bollerslev, T. Leivestad, T. Jenssen, T. K. Hansen, S. Thiel, S. Sagedal, J. Roislien and A. Hartmann: Early posttransplant serum osteoprotegerin levels predict long-term (8-year) patient survival and cardiovascular death in renal transplant patients. J Am Soc Nephrol, 17(6), 1746-54 (2006)

73. P. Secchiero, F. Corallini, A. Pandolfi, A. Consoli, R. Candido, B. Fabris, C. Celeghini, S. Capitani and G. Zauli: An increased osteoprotegerin serum release characterizes the early onset of diabetes mellitus and may contribute to endothelial cell dysfunction. Am J Pathol, 169(6), 2236-44 (2006)

74. J. Schrader, W. Rennekamp, U. Niebergall, M. Schoppet, H. Jahr, M. D. Brendel, D. Horsch and L. C. Hofbauer: Cytokine-induced osteoprotegerin expression protects pancreatic beta cells through p38 mitogenactivated protein kinase signalling against cell death. Diabetologia, 50(6), 1243-7 (2007)

75. G. Steiner, A. Studnicka-Benke, G. Witzmann, E. Hofler and J. Smolen: Soluble receptors for tumor necrosis factor and interleukin-2 in serum and synovial fluid of patients with rheumatoid arthritis, reactive arthritis and osteoarthritis. J Rheumatol, 22(3), 406-12 (1995)

76. M. A. Palladino, F. R. Bahjat, E. A. Theodorakis and L. L. Moldawer: Anti-TNF-alpha therapies: the next generation. Nat Rev Drug Discov, 2(9), 736-46 (2003)

77. P. J. Bekker, D. Holloway, A. Nakanishi, M. Arrighi, P. T. Leese and C. R. Dunstan: The effect of a single dose of osteoprotegerin in postmenopausal women. $J$ Bone Miner Res, 16(2), 348-60 (2001)
78. J. J. Body, P. Greipp, R. E. Coleman, T. Facon, F. Geurs, J. P. Fermand, J. L. Harousseau, A. Lipton, X. Mariette, C. D. Williams, A. Nakanishi, D. Holloway, S. W. Martin, C. R. Dunstan and P. J. Bekker: A phase I study of AMGN-0007, a recombinant osteoprotegerin construct, in patients with multiple myeloma or breast carcinoma related bone metastases. Cancer, 97(3 Suppl), 887-92 (2003)

79. E. M. Schwarz and C. T. Ritchlin: Clinical development of anti-RANKL therapy. Arthritis Res Ther, 9 Suppl 1, S7 (2007)

Abbreviations: DD: Death domain, DD: Death effector domain, DISC: Death-inducing signalling complex, DN: Diabetic nephropathy, GPI: Glycosylphosphatidylinositol, IkB: Inhibitors of kappa B, JNK: c-Jun NH2-terminal kinase, NF-kB: Nuclear factor kappa B, OPG: Osteoprotegerin, RIP: Receptor-interacting protein, TNF: Tumor necrosis factor, TRAIL: TNF-related apoptosis inducing ligand, TRAIL-R/s: TRAIL receptor/s

Key Words: TRAIL, OPG, Kidney, Tumor, Apoptosis, Review

Send correspondence to: Corina Lorz, Molecular Oncology Unit, Edificio 70, Ave. Complutense 22, 28040 Madrid, Spain, Tel: 3491 3460865, Fax: 34913466484 , E-mail: clorz@ciemat.es

http://www.bioscience.org/current/vol14.htm 